\title{
An integrative approach to diagnosing service quality of public parks
}

\author{
Teck-Yong Eng \\ Management Centre, King's College London, London, UK, and \\ Outi Niininen \\ School of Management Studies for the Service Sector, University of Surrey, Guildford, UK
}

\begin{abstract}
Purpose - Aims to examine the services and facilities provided by public parks revealing that the attributes corresponding to performance of service delivery involve the interaction between non-human aspects of physical environment and emotional experience of users which differ from common human aspects of service quality. Also, a service quality programme without reference to other service providers can easily lead to misguided or counterproductive service improvement strategies.

Design/methodology/approach - The present study suggests an integrative approach to diagnosing service quality of public parks that comprises an assessment of performance outcomes and desires to obtain a more comprehensive understanding of service quality and visitor satisfaction as regards frequent users and low users of public parks. Measures pertaining to this approach were examined by a survey of nine public parks in the county of Derbyshire in the UK.

Findings - The results show the effect of individual attributes on visitor satisfaction and their diagnostic value for service improvements. The analysis of desires highlights the differences of pre-visit (prepurchase) evaluation variables between frequent users and low users.

Research limitations/implications - The integrative approach of service quality analysis proposed by this study accounts for the limitations of relying on a single conventional measure of service quality.

Originality/value - The differences may help identify new dimensions for further research and suggest future behavioural intentions such as loyalty and repeat visits. With the knowledge of individual service components that affect overall visitor satisfaction, managers can pin-point areas for improvement to overcome service shortcomings, and allocate scarce resources more effectively.
\end{abstract}

Keywords Performance management, Customer satisfaction, Customer services quality, United Kingdom

Paper type Research paper

An executive summary for managers and executive readers can be found at the end of this article.

\section{Introduction}

With the growing pace of urban lifestyles, public parks are increasingly becoming one of the primary venues for leisure pursuits. Many public parks' organisations such as local councils recognise the importance of offering quality services and facilities in order to meet communities' needs as well as achieve target number of visitors for continued government grants. Although different leisure organisations cater for relatively different types of leisure activities, it is important that such organisations assess customer perceptions of the services and facilities they provide. In particular, visitors' experience of the services and facilities affect their satisfaction and hence return visits. The relationship between encounters and the overall quality of recreation experience is one of the most common

The Emerald Research Register for this journal is available at www.emeraldinsight.com/researchregister

The current issue and full text archive of this journal is available at www.emeraldinsight.com/0887-6045.htm

Journal of Services Marketing

19/2 (2005) 70-80

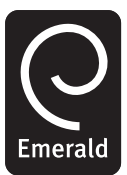

(C) Emerald Group Publishing Limited [ISSN 0887-6045]

[DOI $10.1108 / 08876040510591385]$ research topics in outdoor recreation (e.g. Wagar, 1974; Manning, 1999; Shelby et al., 1989). Yet there little empirical evidence on the usefulness of service quality models and/or techniques for understanding customer satisfaction in the context of public parks (see e.g. Loomis, 2000).

In the marketing services literature, there has been recognition of a direct assessment of the outcomes of service quality as a basis for measuring the performance of service delivery (e.g. Brown et al., 1993; Cronin and Taylor, 1992; Taylor, 1994). It has also been argued that measures used for assessing service quality would need to be useful for diagnosing service shortcomings or excesses (Brown, 1997). The diagnostic aspect of service quality assessment may provide a reference for service providers to pursue service improvement strategies vis-à-vis other service providers. The latter means that service shortcomings (e.g. dissatisfied users) are considered with reference to other providers to avoid counterproductive service improvement strategies or suboptimal allocation of resources. In addition, tourism organisations that respond to the overall satisfaction without knowledge of the effect of individual attributes on customer satisfaction could send mixed signals to park users or amplify the level of dissatisfaction (see Mittal and Lassar, 1998; Mittal et al., 2001).

Although there is evidence that overall service quality and overall visitor satisfaction are positively related to visitors' future behavioural intentions (Tian-Cole et al., 2002), there remains divergent opinions about the nature of this relationship (Stewart and Cole, 2001), and prior research has focused primarily on the disconfirmation of expectations and not much 
on desires of the consumer (Spreng et al., 1996). This raises the question of whether the methods used to study service quality and visitor satisfaction have been inappropriate or inadequate. Past research on service quality in leisure experiences tend to focus on behavioural changes of visitors (e.g. Brunson and Shelby, 1993; Shelby and Vaske, 1991), psychological benefits of leisure experiences (Driver et al., 1991) and demand for different types of recreation experiences (Wagar, 1974). However, little is known about the effects of users' perceptions of service quality and desires on customer satisfaction especially for public park management.

The objectives of the present study are to investigate service quality of the services and facilities provided by public parks based on:

- performance outcomes that contribute to customer satisfaction and service shortcomings or dissatisfaction;

- service quality scores of other public parks within a similar context such as in the same county or region; and

- perceptions and desires of both frequent users and low users of public parks.

There is no presumption that overall visitor satisfaction is influenced only by perceptions and/or dissatisfaction with one or a few attributes would necessarily affect the performance of service delivery compared to other providers. Thus, the purpose of this study is to examine and compare individual components of service quality that influence the level of satisfaction and dissatisfaction of both frequent visitors and low users of public parks. The context of the study comprised of all the public parks within the perimeter of Derbyshire County in the UK.

To accomplish these objectives, this study draws theoretical insights from the marketing services literature. Specifically, it explores performance outcomes of users' perceptions of service quality and desires between frequent users and low users. This approach may avoid logical inconsistencies such as predicting that a consumer who expects and receives poor performance will be satisfied (LaTour and Peat, 1979) and research that sometimes show no relationship between disconfirmation of expectation and satisfaction (e.g. Churchill and Surprenant, 1982). By analysing service quality concepts for determining performance and satisfaction of public park visitors, this study will inform practitioners of service quality measurement in public park management and advance the applicability of methods of service quality analysis.

\section{Background theory}

\section{Expectancy-disconfirmation paradigm}

The dominant theory used in the conceptualisation of both service quality and satisfaction has been based on Oliver's (1980) expectancy-disconfirmation paradigm. While Oliver (1980) proposed that satisfaction is a function of the disconfirmation of performance from expectation, Parasuraman et al. (1985) proposed that service quality is a function of the differences between expectation and performance along the quality dimensions. According to this paradigm, feelings of satisfaction arise when consumers compare their perceptions of a product's performance to their expectations. Confirmation results when the actual performance matches initial expectations. If perceived performance exceeds a consumer's expectations (a positive disconfirmation), then the consumer is satisfied. But if perceived performance falls short of his or her expectations (a negative disconfirmation), then the consumer is dissatisfied.

The popular SERVQUAL model has been conceptualised based on the expectancy-disconfirmation paradigm (Parasuraman et al., 1988). The SERVQUAL model consists of 22 scale items for measuring service quality along five dimensions:

(1) Reliability.

(2) Responsiveness.

(3) Assurance.

(4) Empathy.

(5) Tangibles.

This model has been supported by a considerable amount of empirical evidence (see Yi, 1990) as well as subjected to many criticisms (see Buttle, 1996). Although it often serves as a relevant framework for the identification of service quality attributes, the factors addressed by the model are mainly concerned with the human element of service delivery and tangible aspects of service. There are intangible elements of the services provided by public parks, concerning emotional states beyond a provider's control. Babakus and Boller (1992) suggest the use of performance-based measures of service quality over gap measures. Thus, it seems more appropriate to use performance outcomes as opposed to the difference between perceptions and expectations for evaluation of the services and facilities provided by public parks.

However, literature on the evaluations of experience of nonhuman element of service delivery in the context of leisure parks is very limited. Scholars researching in the field of leisure and park management have frequently turned to social science such as leisure behaviour and the quality of leisure experiences (e.g. McPherson, 1991; Shelby and Heberlein, 1986). Early works on quality of leisure experiences have examined the concept of recreation carrying capacity. For example, Wagar's (1974) work suggests that as the number of people increases, the ability of a recreation area to satisfy some (but not all) recreational motivations will decline, with solitude being the motivation most sensitive to increased use. Similarly, Devall (1973) describes the social organisation of a campground and measuring the carrying capacity of a public park. But this work focused on social organisation of leisure behaviour and sociological factors associated with the use of parks.

In addition, previous studies have mostly dealt with behavioural changes associated with a recreation site or commonly referred to as displacement (e.g. Becker, 1981; Schreyer and Knopf, 1984). Although displacement researchers assume that recreation is goal-oriented and that actors consciously evaluate conditions they experience in light of those goals, little is known about the performance of service attributes and customer satisfaction. Researchers have been most often concerned with leisure attitudes and behaviours with reference to socioeconomic and cultural differences (e.g. Floyd et al., 1993; Tinsley et al., 2002); and behavioural changes associated with displacement (Brunson and Shelby, 1993; Shelby and Vaske, 1991). Others have examined service quality and customer satisfaction with the emphasis on tangible factors (Manning, 1999; Tian-Cole et al., 2002). Previous research has not yet examined and compared the attributes that affect customer satisfaction between frequent users and low users in the context of competing public parks of a county. The relationship between performance of service facilities in public parks and customer satisfaction has remained relatively unexplored. There is little empirical 
evidence on service quality as regards human interactions with the services and facilities provided by public parks.

\section{Desires as a key determinant of satisfaction}

While an assessment of the performance outcomes may capture the level of visitors' satisfaction and likely repeat visits, the services and facilities provided by a public park may not necessarily match a user's desires. In addition to a more comprehensive view of satisfaction based on both performance outcomes and desires (see e.g. Spreng et al., 1996), an understanding of the desires of both frequent users and low users is likely to impact on the overall success of public parks in sustaining and attracting repeat visits. In particular, public parks that have a poor level of service performance or low number of visitors are more likely to gain insights into service delivery problems from low users than frequent users for service improvement strategies such as convert low users to frequent users. Williams (1988) notes that the concept of total satisfaction in terms of the quality of recreation experiences may be both limiting and unnecessary. This is mainly because many satisfaction scales have simply asked for an evaluation of trip quality, rather than how "satisfied" people are (Shelby and Heberlein, 1986, p. 130). Hall and Shelby (2000) point out that users who have frequented a site in the past and judged it as unsuitable for attainment of desired experiences are mostly likely to move elsewhere. The impact of desires on prepurchase choice or evaluation processes has been noted in the satisfaction literature (see Payne et al., 1993). Furthermore, recognition of users' desires is consistent with the social and cultural values of open space or public park (Thompson, 2002).

However, there is not yet consensus about the conceptual definition of the desires construct. Desires have been defined at various levels of abstraction, ranging from higher- to lowerlevel desires as connected in a means-end chain (Gutman, 1982). The higher-level values and desires lead to desires for products that provide certain benefits, and these benefits in turn specify the attributes and the levels of attributes desired in the product. The lower-level desires can mean the most basic and fundamental needs, life goals, or desired end-states or more concretely in terms of the means that a person believes will lead to the attainment of the desired end-states. There is some precedent in the satisfaction literature that defines desires at an abstract level (e.g. Westbrook and Reilly, 1983). In the context of this study, desires refer to the higherlevel values associated with the attributes such as services and facilities of public parks, which could include existing services and facilities or those desired or absence in the parks. This definition encompasses visitors' evaluation of expectations that impact on their levels of satisfaction and may reduce the emphasis on positive attributes of performance outcomes. For example, the relevance and representativeness of internal perceptions and the eventual performance outcomes have been questioned (Hopkins et al., 1990).

Service quality of public parks is not limited to services and facilities in the park but may include intangible and nonhuman aesthetic features such as landscape, atmosphere and artistic appeals (Brown, 1988). Such intangible and nonhuman features of public parks are concerned with desires of users not identified by performance attributes. For example, an assessment of performance outcomes based on tangible aspects of the services and facilities provided by public parks may not capture the aesthetic features. Also, improvement on the services and facilities may not necessarily enhance the level of satisfaction or attract higher number of visitors. This is not only because the service provider has a finite knowledge of how a particular service would be perceived by every visitor, but also certain negative service performance attributes may have a greater impact on the visitor total experience. It therefore makes sense to examine visitors' and low users' desires in terms of positive and negative service performance attributes that relate to satisfaction (cf. Gardial et al., 1994). Since the assessment of desires is mostly concerned with prepurchase evaluations, the inclusion of this measure may also help elicit new service quality dimensions for public park management.

\section{Diagnostic power of service quality analysis}

As noted above, it is possible that insight into negative performance attributes of service quality can be useful for diagnostic purposes. Mittal and Lassar (1998) found that negative performance of an attribute has a greater impact than positive performance for both overall satisfaction and repeat purchase. In this respect, managers are often advised to plot expectation and performance scores and judge the company's performance against a "zone of tolerance", (i.e. the range between consumers' minimum and desired levels of expected service) (Brown, 1997). This approach may offer greater diagnostic value than merely taking the difference between expectations and perceptions (Parasuraman et al., 1994). But managerial decisions guided by the scores of overall satisfaction based on an immediate postpurchase evaluative judgment or an affective reaction to the most recent transactional experience with the firm (Oliver, 1993) do not indicate individual attributes of the cumulative satisfaction construct. In other words, it has a low diagnostic power of service quality or could accentuate the level of dissatisfaction (Mittal et al., 2001) or lead to suboptimal allocation of scarce resources (Brown, 1997). Ganesh et al. (2000) note that an understanding of individual attributes that affect overall satisfaction enables organisations to determine which components of the service are more important than others in determining overall satisfaction. In contrast to previous studies about the effects of encounters on leisure experience (e.g. Burch 1981, 1984), diagnostic evaluation of service attributes is likely to provide guidance for managers in overcoming quality excesses and/or shortcomings.

Although individual attributes of satisfaction and dissatisfaction can be determined, measurement of service quality based on absolute attributes of the services and facilities provided by a specific public park could mask the true shortcomings that exist compared to other competing public parks. The problem with absolute meaning is that there is no frame of reference beyond the attributes considered either diagnostically superior or inferior. In addition, taking the difference between performance outcomes and expectations can be misleading because of the likely inequivalence of scale units on the scales being compared (also known as comparative meaning problem) (Lynch et al., 1991). The assumption of equivalent scale units must be satisfied for a meaningful comparison unless a reference group can be established. The latter is referred to as the establishment of norms (Brown, 1997). Norms are the distribution of scores obtained on a measure by a group of similar entities or individuals (the "reference group") based on Churchill's (1979) steps for the development of good 
measures. In the context of this study, rather than measuring service quality and satisfaction of visitors of a single public park, an average score is obtained for the attributes of various public parks offering similar leisure pursuits. This is practical and analogous to the population-based norms that offer diagnostic frame of reference against those of a population of similar public parks. Prior research on leisure parks and service quality has mainly obtained data from one park that have limited diagnostic value.

An overview of the above literature suggests that different concepts of service quality, empirical research and conceptual discussions provide insights for analysing service quality and user satisfaction of public parks. This can be represented in Figure 1. As shown, this approach to service quality analysis is unconventional in that, it draws on several theoretical concepts and suggests possible practical remedies for some of the weaknesses associated with service quality assessment. More significantly the integrative approach contributes to decision-making and service quality analysis in public park and leisure management by examining and exploring theoretical concepts of service quality in a largely neglected research context of public park services and facilities.

\section{Method}

The sample of respondents was randomly selected from nine public parks in the Derbyshire County of the UK. Frequent users include those that visited public parks more than three times a month whereas low users visited public parks not more than twice a month. This means that frequent users could be visiting the public park at least once a week. Both frequent users and low users of public parks were screened and interviewed within the public park itself as well as in the town centre outside the park. The survey method of street interview was employed. Since people may visit parks at different times of the day, the researchers used a fieldwork schedule with fixed three hours intervals from morning till evening throughout the day over one weekend period for each park. The fieldwork was carried out simultaneously for both frequent users and low users using the same schedule. A standard questionnaire was used to guide the research and ensure consistency of questions for the interviews.

A total of 1,745 respondents participated, of which 450 were frequent users and 1,295 were low users of public parks. As expected, the total number of response from low users was larger than frequent users. This was not a major concern because each sample was analysed separately as well as the sample size of frequent users was relatively large to provide sufficient variance in the data. More important was identifying and examining performance attributes related to frequent users and low users as regards the quality of services and facilities provided by public parks. The profile of majority frequent users and low users can be summarised respectively as follows, for the frequent users: 41 per cent fell in the age group of 16-34 and the rest mostly from the age group of 35-64; 36 per cent had more than two children; and 61 per cent were married. In the case of low users, 33 and 22 per cent were from the age group of 16-34 and 35-64 respectively; 29 per cent had more than two children; and 57 per cent were married.

Scale items for measuring service quality of the services and facilities provided by public parks were adapted from the element of human interaction/intervention (e.g. Mills and Morris, 1986) and the element of physical facility, also known as "servicescapes" (Bitner, 1992). The human aspects of service delivery (such as the effect of atmospherics, appearance of facility, design, decor elements, etc.) have been well recognised in the services marketing literature. For example, of the five SERVQUAL's dimensions, four, namely, reliability,

Figure 1 An integrative approach to service quality analysis

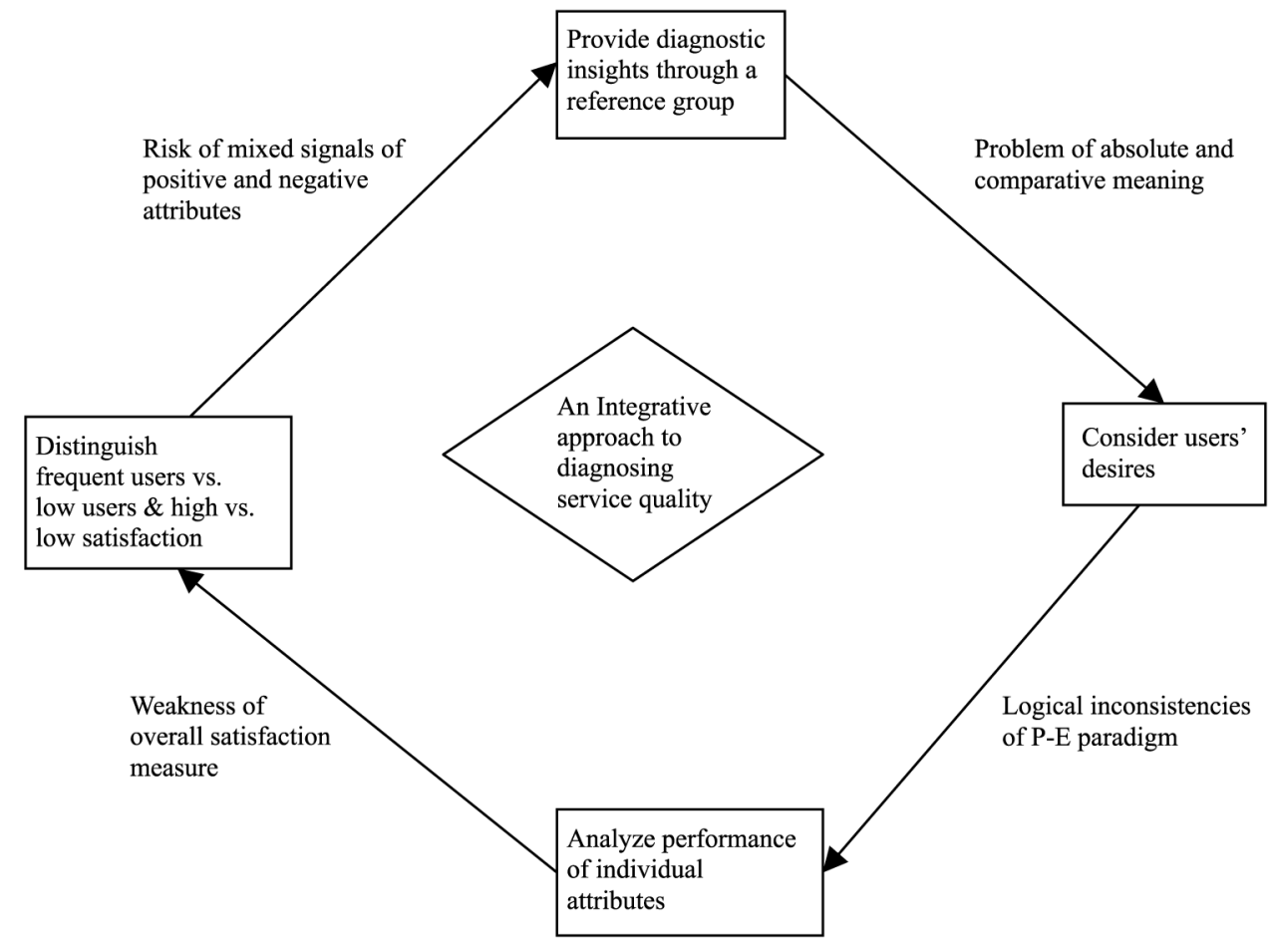


responsiveness, assurance and empathy, correspond to this factor of human element in the service delivery. The servicescapes are concerned with the effect of physical facility, equipment, personnel and communication materials on customers. This can influence customers in numerous ways, e.g. physiological, psychological, sociological and cognitive. The items for this study are developed from both the element of human interaction and servicescapes with specific reference to the provision of public park services and facilities.

The final survey instrument consists of 25 items and has been developed based on comments and suggestions from three leisure park managers and two researchers considered expert in the field of services marketing. In addition, a small pre-test based on 20 local residents in the area was conducted to check relevance and reliability of the research instrument. Due to limited past empirical studies on public parks and the goal of examining a respondent's desires, additional questions on: the reasons for not using the public parks, ways to improve the parks, factors considered prior to visiting a public park and whether they would recommend the park to others were included. These open-ended questions provided a more qualitative approach as suggested by Edvardsson and Mattesson (1993) for understanding service quality. In order to examine both positive and negative attributes associated with service quality, respondents were asked to select and rank attributes that they were satisfied and dissatisfied with the public parks. The items examined are shown in tables of the results section. Responses to the items were measured on seven-point Likert-type scaled anchored by “extremely poor" (1) and "excellent" (7).

The data analysis involved three stages using multiple response and cross-tab analyses:

(1) Identification of performance outcomes in terms of the attributes affecting visitor satisfaction and dissatisfaction.

(2) Comparison of the significance of the individual attributes and the level of overall satisfaction between public park frequent users and low users.

(3) Categorisation of commonly stated desires for both public park frequent users and low users.

The significance of the results as regards individual attributes of satisfaction versus dissatisfaction was compared using a $t$-test. The results are tabulated and discussed in the next section.

\section{Results}

Table I illustrates, in summary form, the mean performance outcomes with positive and negative attributes in relation to visitor satisfaction of the services and facilities provided by public parks. In the first instance, each attribute is considered individually to avoid the implicit assumption that positive and negative attributes associated with public parks' services and facilities would be correlated or related in an asymmetrical fashion to the overall level of satisfaction. As shown, different attributes have different degrees of impact on visitor satisfaction, for example, comfortable settings (58 per cent) emerged as the most important priority for frequent park visitors. This is followed by landscape (48 per cent) and maintenance of park ( 34 per cent). In contrast, low users of public parks noted convenience (53 per cent), comfortable settings ( 51 per cent) and space provided by public parks (38 per cent) as important positive attributes that contribute to visitor satisfaction. More interestingly, the results show individual attributes that cause visitor dissatisfaction, mainly with children playgrounds ( 67 per cent), personal safety (52 per cent), quality of refreshments ( 49 per cent) and range of facilities (43 per cent) for frequent visitors. Low users were also highly dissatisfied with the same attributes except in the order of range of facilities (72 per cent), quality of refreshments (63 per cent), children playgrounds (58 per cent) and personal safety (49 per cent). It can be noted that the extent to which negative attributes affect visitor dissatisfaction were more highly rated than positive attributes particularly for low users. In other words, negative performance of an attribute may have a greater impact than positive performance on overall visitor satisfaction. As shown in Table I, both frequent users and low users were mostly satisfied with tangible aspects of service delivery such as aesthetic appeals but parks' facilities (e.g. range of facilities and children playgrounds) and customer service seem to be the main shortcomings that cause visitor dissatisfaction. The results indicate that both frequent users and low users shared similar views on most of the attributes that either have positive or negative impact on their experience.

Table II depicts the mean satisfaction of individual attributes for both frequent users and low users. In order to examine the impact of each attribute on visitor satisfaction, low versus high satisfaction groups were created by mean split based on the value of mode, and the lowest and highest scores. The significance between low and high satisfaction groups were compared using a $t$-test. This procedure is consistent with the notion of understanding individual attributes (Ganesh et al., 2000) as well as recreation is often described as high or low (Loomis, 2000). The results highlight attributes that have significant impact on satisfaction for both low and high satisfaction groups. While visitor satisfaction as regards positive and negative attributes may indicate service delivery problems (see Table I), it does not indicate the significance of each attribute between low and high satisfaction groups. The latter is relevant for diagnostic as well as for pragmatic reasons, as service providers need to address performance shortcomings that have the most impact on customer satisfaction and allocate scarce resources effectively.

As noted in Table II, the mean attributes related to good facility, landscape, range of facilities, convenience and experience at the park were significant for both low and high satisfaction groups of frequent users. This suggests that they are high on the priority list of public park services and facilities that affect both low and high satisfaction groups significantly. For example, the mean of frequent user for good facility were 5.76 and 5.96 for low and high satisfaction groups respectively with a $t$-value of 4.52 . This was significant at the 0.00 level. The results indicate that changes in the level of service and standards of facility associated with the attributes identified above would a have significant impact on visitor satisfaction. This seems to support the positive and negative attributes noted by respondents in Table I that is, the range of facilities and children playgrounds were the main shortcomings causing dissatisfaction. Also, the range of facilities and experience at the park were significant for the low and high satisfaction groups of low users. It can be seen that the mean of overall satisfaction itself would not indicate the significance of the attributes in terms of individual effects on satisfaction. In particular, the mean difference between low and high satisfaction groups is rather small, indicating 
Table I Perceived positive and negative attributes

\begin{tabular}{|c|c|c|c|c|c|}
\hline Rank & Frequent users & Frequency (\%) & Rank & Low users & Frequency (\%) \\
\hline \multicolumn{6}{|c|}{ Positive } \\
\hline 1 & Comfortable settings & 58.1 & 1 & Convenience & 53.2 \\
\hline 2 & Landscape & 47.6 & 2 & Comfortable settings & 50.7 \\
\hline 3 & Maintenance & 33.9 & 3 & Spacious & 38.2 \\
\hline 4 & Visually appealing & 32.4 & 4 & Landscape & 27.5 \\
\hline 5 & Parking & 30.5 & 5 & Maintenance & 25.0 \\
\hline 6 & Cleanliness & 28.2 & 6 & Visually appealing & 26.9 \\
\hline 7 & Convenience & 21.4 & 7 & Cleanliness & 21.5 \\
\hline 8 & Experience at the park & 19.5 & 8 & Parking & 17.3 \\
\hline 9 & Staff & 17.8 & 9 & Facility & 14.2 \\
\hline 10 & Spacious & 15.4 & 10 & Staff & 12.6 \\
\hline 11 & Reasonable charges & 14.8 & 11 & Trust & 11.4 \\
\hline 12 & Signage & 14.6 & 12 & Reasonable charges & 10.2 \\
\hline 13 & Reputation & 13.7 & & & \\
\hline 14 & Trust & 12.3 & & & \\
\hline \multicolumn{6}{|c|}{ Negative } \\
\hline 1 & Children's playgrounds & 67.2 & 1 & Range of facilities & 72.4 \\
\hline 2 & Personal safety & 51.7 & 2 & Quality of refreshments & 63.1 \\
\hline 3 & Quality of refreshments & 49.1 & 3 & Children's playgrounds & 57.9 \\
\hline 4 & Range of facilities & 42.8 & 4 & Personal safety & 49.3 \\
\hline 5 & Information & 31.8 & 5 & Service level & 42.8 \\
\hline 6 & Events & 20.4 & 6 & Responsive & 37.1 \\
\hline 7 & Service level & 19.2 & 7 & Information & 22.7 \\
\hline 8 & Responsive & 18.6 & 8 & Events & 16.3 \\
\hline 9 & Customers' choice & 16.9 & 9 & Public transport & 15.8 \\
\hline 10 & Public transport & 15.6 & 10 & Signage & 14.4 \\
\hline \multirow[t]{3}{*}{11} & Facility & 14.2 & 11 & Reputation & 13.5 \\
\hline & & & 12 & Experience at the park & 12.7 \\
\hline & & & 13 & Customers' choice & 10.2 \\
\hline
\end{tabular}

small deviation and the importance of most of the attributes in influencing the level of satisfaction.

The results show that the attributes having the most important impact on visitor satisfaction for both frequent and low users had a significantly higher mean of high satisfaction group compared to low satisfaction group. For instance, both comfortable settings and convenience in terms of accessibility had a significant mean of satisfaction as well as high positive impact on visitor satisfaction (see Table I). But the mean of service level for the two satisfaction groups between frequent (4.23 and 4.93) and low users (4.51 and 4.71) was rather low. The level of service provided by public parks was also noted as one of the major causes of visitor dissatisfaction particularly for low users. This highlights the importance of customer service as one of the main areas for service improvement with regards to the provision of facilities, and organisation of events by public parks. The significance of the low and high satisfaction groups of both frequent and low users for the attribute of staff in being helpful and courteous suggests that interactions between park personnel and visitors play an important role in achieving high visitor satisfaction. Although it could be argued that the mean of low satisfaction may indicate acceptable level of overall satisfaction, dividing users into low and high satisfaction groups provide a more reliable diagnosis of the impact of individual attributes on overall satisfaction than using the mean of satisfaction alone. For example, most the mean values of low users were lower than those of frequent users. The results indicate the difference and significance between low and high satisfaction groups that help identify and prioritise problem areas for both low and high satisfaction groups.

Despite the relatively high mean of satisfaction, the mean of low satisfaction group can be significant for both frequent and low users (e.g. range of facilities, good events, customer's choice for frequent users). This suggests that high mean of satisfaction may mask the presence of underlying low level of dissatisfaction for some visitors. A comparison of the overall mean of satisfaction between low and high satisfaction groups shows that the difference between the mean values was small. While this may be caused by the effect of averaging individual attributes, the large number of attributes examined in the assessment of service quality highlights the importance of understanding the impact of individual service components on customer satisfaction.

Table III illustrates, in a summary form the results of respondents' desires concerning the use of public parks for leisure. Desires were examined in terms of what public park providers could do to encourage more frequent visit, suggestion of ways to improve public parks, and services and facilities considered prior to visiting a public park. The five most common reasons noted by low users that would encourage more frequent visit in the order of frequency were: 
Table II High vs low satisfaction groups

\begin{tabular}{|c|c|c|c|c|c|c|}
\hline \multirow[b]{2}{*}{ Attributes } & \multicolumn{2}{|c|}{$\begin{array}{l}\text { Frequent users mean } \\
\text { Satisfaction groups }\end{array}$} & \multirow{2}{*}{$\begin{array}{l}t \text {-value } \\
(p \leq n)\end{array}$} & \multicolumn{2}{|c|}{$\begin{array}{c}\text { Low users mean } \\
\text { Satisfaction groups }\end{array}$} & \multirow{2}{*}{$\begin{array}{c}t \text {-value } \\
(p \leq n)\end{array}$} \\
\hline & Low & High & & Low & High & \\
\hline Comfortable settings & 5.12 & 6.05 & $3.12(0.00)$ & 4.43 & 6.34 & $4.64(0.01)$ \\
\hline Children's playgrounds & 4.81 & 5.21 & $2.65(0.00)$ & 3.04 & 4.75 & $2.76(0.00)$ \\
\hline Maintenance & 4.13 & 6.19 & $2.71(0.02)$ & 3.13 & 5.16 & $3.94(0.00)$ \\
\hline Visually appealing & 5.16 & 5.98 & $3.64(0.00)$ & 4.77 & 6.58 & $2.81(0.00)$ \\
\hline Range of facilities & 5.73 & 6.12 & $4.12(0.01)$ & 5.16 & 5.49 & $4.32(0.00)$ \\
\hline Spacious & 4.10 & 4.97 & $3.95(0.00)$ & 5.36 & 6.81 & $4.61(0.01)$ \\
\hline Good facility & 5.76 & 5.96 & $4.52(0.00)$ & 4.53 & 5.90 & $4.01(0.00)$ \\
\hline Good events & 4.61 & 6.74 & $4.37(0.01)$ & 5.68 & 5.92 & $3.61(0.01)$ \\
\hline Landscape & 5.15 & 6.37 & $4.34(0.00)$ & 4.53 & 5.89 & $3.71(0.00)$ \\
\hline Cleanliness & 5.78 & 6.41 & $3.42(0.03)$ & 4.18 & 5.56 & $4.41(0.00)$ \\
\hline Convenience & 5.16 & 5.74 & $3.29(0.00)$ & 4.92 & 6.64 & $4.10(0.00)$ \\
\hline Signage & 4.13 & 4.53 & $3.17(0.00)$ & 4.30 & 5.06 & $2.41(0.02)$ \\
\hline Parking & 4.12 & 4.56 & $3.25(0.01)$ & 4.76 & 6.12 & $3.61(0.01)$ \\
\hline Public transport & 4.89 & 5.11 & $2.16(0.04)$ & 4.13 & 4.54 & $2.58(0.03)$ \\
\hline Reasonable charges & 4.05 & 4.63 & $3.54(0.01)$ & 4.45 & 5.16 & $3.53(0.00)$ \\
\hline Experience at the park & 3.96 & 4.82 & $3.94(0.00)$ & 5.40 & 6.12 & $4.13(0.00)$ \\
\hline Personal safety & 4.78 & 5.39 & $3.36(0.00)$ & 4.98 & 5.27 & $3.42(0.01)$ \\
\hline Reputation & 4.34 & 4.91 & $3.61(0.01)$ & 5.35 & 5.81 & $3.64(0.00)$ \\
\hline Quality of refreshments & 4.63 & 5.21 & $3.54(0.01)$ & 4.92 & 5.31 & $3.81(0.03)$ \\
\hline Information & 4.91 & 5.36 & $2.02(0.03)$ & 4.65 & 5.26 & $4.13(0.00)$ \\
\hline Service level & 4.23 & 4.98 & $4.08(0.00)$ & 4.51 & 4.71 & $4.53(0.01)$ \\
\hline Customers' choice & 4.79 & 6.38 & $3.91(0.01)$ & 5.37 & 5.81 & $2.84(0.04)$ \\
\hline Trust & 4.18 & 5.06 & $2.64(0.01)$ & 4.31 & 4.56 & $2.76(0.00)$ \\
\hline Staff & 4.12 & 5.14 & $3.97(0.00)$ & 4.87 & 5.92 & $4.13(0.01)$ \\
\hline Responsive & 6.17 & 6.28 & $3.43(0.00)$ & 5.01 & 5.39 & $3.79(0.00)$ \\
\hline Overall mean & 4.56 & 5.52 & & 4.66 & 5.60 & \\
\hline
\end{tabular}

Notes: Mean scores for low and high satisfaction groups were formed via mean split for each attribute, depending on the value of mode, and the lowest and highest scores. The anchors used were 1 (extremely poor) and 7 (excellent)

publicised information about services and facilities provided by public parks, change plants and landscape according to time of year, improved safety for visitors and children, accessibility to shops for snacks and refreshments, and provide track for joggers and runners. These suggestions by low users highlight some of the shortcomings of public parks and users' desires. For example, improved safety and accessibility to shops address the negative aspect identified earlier in the performance outcomes of public parks. The other suggestions seem to deal with low users' desires that have positive impact on satisfaction or may increase their frequency of visits.
By way of contrast, frequent users were asked about ways to improve the services and facilities of public parks. The five most common suggestions given by frequent users were: organised recreational activities for children, improved safety particularly better lighting in car parks, good maintenance of facilities, better communications of the events, services and facilities provided by public parks such as broadcast by local radio station, and creative use of space and preserve natural environment. It seems that frequent users are more concerned with the practical aspect of quality and value of services provided by public parks compared to low users. For example, the common suggestions focus on improving the standard of

Table III Common reasons, suggestions and prior visit consideration related to visitors' satisfaction

\begin{tabular}{|c|c|c|c|}
\hline \multirow[b]{2}{*}{ Reasons for less frequent/low users } & \multirow[b]{2}{*}{ Suggestions by frequent users } & \multicolumn{2}{|c|}{ Prior visit consideration users } \\
\hline & & Frequent & Low \\
\hline Information about service and facilities (67 per cent) & Recreational activities for children (64 per cent) & Parking convenience & Appearance \& landscape \\
\hline Landscape design and time of year (59 per cent) & $\begin{array}{l}\text { Improved safety, particularly better lighting } \\
\text { (60 per cent) }\end{array}$ & Children-friendly & Peaceful \\
\hline Improved safety (51 per cent) & Good maintenance of facilities (52 per cent) & Cleanliness & Facilities \\
\hline Accessibility to shops (47 per cent) & Improved means of communications (49 per cent) & $\begin{array}{l}\text { Availability of diverse } \\
\text { activities }\end{array}$ & Historic values \\
\hline Track for joggers and runners (38 per cent) & $\begin{array}{l}\text { Creative use of space and preserve natural } \\
\text { environment ( } 33 \text { per cent) }\end{array}$ & Personal safety & Playgrounds for children \\
\hline
\end{tabular}


existing services and better utilisation of resources such as creative use of space. They had not been examined in the assessment of performance outcomes. Since the majority of frequent users suggested the above, improving or raising the standard of service with regards to the areas of concern are likely to enhance the level of user satisfaction. Furthermore, the results are obtained from relevant but different public parks within a similar context. There is diagnostic value and relevance from the analysis. As such, service improvement strategies can be directed effectively to address pertinent factors to improve service quality.

While addressing the above suggestions made by frequent and low users may increase customer satisfaction, the focus on improvement alone may not necessarily capture users' desires in the evaluation of pre-visit decision-making. As shown in Table III, both frequent and low users were asked to provide information about service or facility related factors that influence their decision-making prior to visiting a public park. It can be seen that frequent and low users have relatively distinct types of services and facilities considered to be important in their pre-visit decision-making. The five most common factors noted by frequent users were: convenience for parking, children friendly, cleanliness, diverse range of facilities for adults and children, and personal safety. It seems that these attributes are basic essentials that users expect from public parks. In contrast, low users noted appearance of the park, peace and relaxation, range of facilities, historical values and playgrounds for children as five of the most important considerations. These results provide some insights into the needs and desires of low users that are important not only for attracting new visitors but also repeat visits. For example, users' experiences of the qualities that appeal to them are likely to determine future return visit. In addition to the extent of the importance of the factors considered prior to visiting a public park, respondents were asked whether would recommend others to visit the public park. On this account, about 68 per cent of frequent users and 49 per cent of low users have said "yes," which seems to suggest that low users' desires may have some effect on the prior visit decisionmaking based on the willingness to recommend the public park to others. Thus, the relatively different types of desires between frequent users and low users suggest that fulfilling the needs of low users may attract more regular visits by low users whereas the same action may not have a large effect on the perceived level of satisfaction for existing frequent users.

\section{Discussion}

This section details the main implications of the results from the preceding section. The results clarify the importance and relevance of assessing service quality based on performance outcomes of individual service attributes. In addition, the assessment of both perceived positive and negative attributes of service performance is useful for diagnosing service quality problems. This diagnostic insight is important not only because there has been limited past research on service quality of public parks, but also the plethora of attributes unique to public parks, namely, the interaction between non-human aspects of physical environment in public parks and emotional experience of users differ from common human aspects of service quality (e.g. SERVQUAL).

The results of this study indicate that performance of individual attributes differed in terms of their impact on customer satisfaction. Also, the extent of negative attributes noted to have caused dissatisfaction may affect overall customer satisfaction more profoundly than positive attributes. A detailed analysis of the mean between low and high satisfaction groups for both frequent and low users reveals the mean of satisfaction and significance of individual attributes in affecting visitor satisfaction. This provides diagnostic value for identifying attributes that affect both low and high satisfaction groups as well as cause major customer dissatisfaction. It was noted that the high mean of overall satisfaction may mask the presence of underlying low level of satisfaction with certain attributes. This suggests that changes in quality of service performance may cause satisfaction or dissatisfaction. For example, by providing more information about services and facilities provided by public parks may raise perceptions of performance but at the same time may increase disconfirmation and decrease satisfaction with the information given (Boulding et al., 1993). It is therefore important to examine individual attributes related to low and high satisfaction groups, and compare the significance as regards overall satisfaction against other public parks. But further research is needed to establish more clearly the relationship between individual attributes and combination of attributes, and their impact on overall satisfaction for greater diagnostic insights.

The present research also shows that there are some differences in the significance of attributes affecting customer satisfaction between frequent and low users. Although both frequent and low users noted relatively similar attributes that cause customer dissatisfaction, insights from the mean satisfaction between low and high satisfaction groups as well as from the suggestions made by frequent and low users indicate some differences in terms of impact on visitor satisfaction. The difference in the importance attached to certain attributes by frequent and low users suggests that it may not be adequate to assess service quality without meaningful distinction of users. It is not the purpose of this study to identify and exhaust different types of users but it is important to recognise the potential effect of service improvement strategies on target segments of individual service providers. In the case of this study, the analysis takes into account other similar public parks to reduce the problem of absolute and comparative meaning. For example, service improvement strategies can be directed toward improving performance in those areas that are crucial to performance compared to other providers for both frequent and low users. From a diagnostic viewpoint, further research is needed to examine the extent to which improvement on services identified by frequent users and low users would enhance overall customer satisfaction and increase repeat visits.

Some scholars have noted the importance of desires as a standard comparison when forming satisfaction judgments (e.g. Spreng et al., 1996). But few empirical studies have examined this construct as part of visitor satisfaction mainly because of operationalisation and/or measurement difficulties. It has been shown in this study that internal perceptions of service quality derived from previous literature and management judgment may not necessarily represent frequent users and low users' desires. In this instance, the factors noted in the pre-visit evaluation of public parks were by and large different from the service attributes examined as well as between frequent users and low users. In the case of frequent users, there were minor differences between 
performance outcomes and desires, which suggest that to maintain the status quo would have little impact on satisfaction. As Spreng et al. (1996) note, when a consumer has purchased and used a product many times (presumably it is meeting his or her desires) such as many visits to a public park by frequent users, the difference between expectations and performance received would be small. Conversely, the analysis sheds light on low users in terms of the factors for service improvement, and the potential for public park providers to understand pre-visit evaluation processes. Thus, incorporating desires into service quality analysis may help management identify gap of performance outcomes based on expectations (cf. LaTour and Peat, 1979) - though further research is required to investigate whether addressing the desires would satisfy low users' needs, and how such action would impact on overall satisfaction of existing frequent users.

Finally, the results of this study could be used to provide some insights for the development of measures about the relative importance of desires, such as by identifying factors related to a visitor's desires. It is worth noting that this paper is a first step in attempting to understand the roles of desires and performance outcomes in the assessment of service quality and visitors' satisfaction with reference to a group of similar public parks. In order to avoid logical inconsistencies of the disconfirmation of expectations model particularly for an under-researched topic on service quality of public parks, the results of this study indicate that direct assessment of performance outcomes coupled with qualitative insights from respondents' desires could help park managers identify some of the pitfalls of service quality measurement identified in Figure 1. Also, with the assessment of similar service providers to ensure relevance, the analysis provides useful diagnostic insights for improvement strategies against similar public parks within the same context. Thus, consistent with Boulding et al. (1993) and Spreng et al.'s (1996) work, researchers examining service quality issues might consider analysing performance outcomes and desires individually as a means of gaining useful diagnostic information about service performance and visitor satisfaction.

\section{Concluding remarks}

This study draws on a number of existing theoretical concepts of service quality, namely the notion of a direct assessment of performance outcomes (e.g. Cronin and Taylor, 1992), a diagnostic approach by considering other similar providers (Brown, 1997), and an analysis of desires as part of customer satisfaction formation process (Spreng et al., 1996). Such an integrative approach of service quality analysis for public parks seems to be more comprehensive, in that it accounts for the limitations of relying on a single conventional measure of service quality. Specifically, this study gives insight into current understanding of the attributes or factors that impact on service quality and customer satisfaction. In order to assess service shortcomings or excesses, positive and negative attributes were examined, and they were represented in low and high satisfaction groups, which help identify and prioritise important service attributes affecting both low and high satisfaction groups. The introduction of the analysis of desires has provided useful insights into factors that influence visitors' decision prior to visiting a public park. In particular, the present research elicited differences of pre-visit (prepurchase) evaluation variables between frequent users and low users. The differences may help identify new dimensions for further research and suggest future behavioural intentions such as loyalty and repeat visits. This is consistent with the recent call for more research in examining behavioural and cultural factors of public park users (Thompson, 2002).

The results of this study also have important implications for public park and leisure management. The issues highlighted by low satisfaction groups and low users can serve as benchmarks for providing a minimum level of service to the public and local communities; and service improvement guidelines for increasing customer satisfaction and attracting more visitors. With the knowledge of individual service components that affect overall visitor satisfaction, managers can pinpoint areas for improvement to overcome service shortcomings, and allocate scarce resources more effectively. This is crucial because scores obtained for the overall mean of visitor satisfaction alone may not account for true service deficiencies. In addition, the risk of users in the low satisfaction groups spreading negative word-of-mouth about the services and facilities provided by a specific public park could have severe impact on marketing efforts. In this sense, assessment of service quality needs to be diagnostic in order to address factors causing customer dissatisfaction as effectively as possible, given the constraints of funds from the government. An understanding of the reasons affecting the number of park visitors allows managers to develop strategic partnership with other public services in providing ancillary services that impact on visitors' total experience such as local transportation service and public facilities. At a more strategic level, an understanding of frequent users and low users' desires provide valuable insights for planning marketing strategy to enhance visitor satisfaction and attract more visitors. On the whole, this calls for an integrative approach to service quality analysis, as suggested in this study.

\section{References}

Babakus, E. and Boller, G. (1992), "Empirical assessment of SERVQUAL scale", fournal of Business Research, Vol. 24, pp. 253-68.

Becker, R.H. (1981), "Displacement of recreational users between the lower St Croix and Upper Mississippi rivers", Fournal of Environmental Management, Vol. 13, pp. 259-67.

Bitner, M.J. (1992), "Servicescapes: the impact of physical surroundings on customers and employees", fournal of Marketing, Vol. 56, pp. 57-71.

Boulding, W., Kalra, A., Staelin, R. and Zeithaml, V.A. (1993), "A dynamic process model of service quality: from expectations to behavioural intentions", Fournal of Marketing Research, Vol. 30, pp. 7-27, February.

Brown, P.J. (1988), "Quality in recreation experience", in Watson, A.H. (Ed.), Outdoor Recreation Benchmark, Proceedings of the National Recreation Forum, General Technical Report SE-52, US Forest Service, Asheville, NC, pp. 412-21.

Brown, T.J. (1997), "Using norms to improve the interpretation of service quality measures", Fournal of Services Marketing, Vol. 11 No. 1, pp. 66-80.

Brown, T.J., Churchill, G.A. Jr and Peter, J.P. (1993), "Improving the measurement of service quality", fournal of Retailing, Vol. 69 No. 1, pp. 127-39. 
Brunson, M.W. and Shelby, B. (1993), "Recreation substitutability: a research agenda", Leisure Sciences, Vol. 15, pp. 67-74.

Burch, W.R. Jr (1981), "The ecology of metaphor: spacing irregularities for humans and other primates in urban and wildland habitats", Leisure Sciences, Vol. 4, pp. 213-31.

Burch, W.R. Jr (1984), "Much ado about nothing: some reflections on the wider and wilder implications of social carrying capacity", Leisure Sciences, Vol. 6, pp. 487-96.

Buttle, F. (1996), "SERVQUAL: review, critique, research agenda", European fournal of Marketing, Vol. 30 No. 1, pp. 8-32.

Churchill, G.A. Jr (1979), “A paradigm for developing better measures of marketing constructs", fournal of Marketing Research, Vol. 16, February, pp. 64-73.

Churchill, G.A. and Surprenant, C. (1982), "An investigation into the determinants of consumer satisfaction", fournal of Marketing Research, Vol. 19, November, pp. 491-504.

Cronin, J.J. and Taylor, S.A. (1992), "Measuring service quality: a reexamination and extension", fournal of Marketing, Vol. 56, July, pp. 55-68.

Devall, W.B. (1973), "The development of leisure: social worlds", Humboldt fournal of Social Relations, Vol. 1, pp. 53-9.

Driver, B., Tinsley, H. and Manfredo, M. (1991), "The paragraphs about leisure and recreation experience preference scales: results from two inventories designed to assess the breadth of the perceived psychological benefits of leisure", in Driver, B., Brown, P. and Peterson, G. (Eds), Benefits of Leisure, Venture Publishing, State College, PA, pp. 263-86.

Edvardsson, B. and Mattesson, J. (1993), "An experiencebased measure of service quality", Service Industries fournal, Vol. 13 No. 4, pp. 17-29.

Floyd, M.F., Gramann, J.H. and Saenz, R. (1993), "Ethnic factors and the use of public outdoor recreation areas: the case of Mexican Americans", Leisure Sciences, Vol. 15, pp. 83-98.

Ganesh, J., Arnold, M.J. and Reynolds, K.E. (2000), "Understanding the customer base of service providers: an examination of the differences between switchers and stayers", fournal of Marketing, Vol. 64 No. 2, pp. 65-87.

Gardial, S.F., Clemons, D.S., Woodruff, R.B., Schumann, D.W. and Burns, M.J. (1994), "Comparing consumers' recall of prepurchase and postpurchase product evaluation experiences", fournal of Consumer Research, Vol. 24, March, pp. $548-60$.

Gutman, J. (1982), "A means-end chain model based on consumer categorization processes", Fournal of Marketing, Vol. 46, Spring, pp. 60-72.

Hall, T. and Shelby, B. (2000), "Temporal and spatial displacement: evidence from a high-use reservoir and alternate sites", Fournal of Leisure Research, Vol. 32 No. 4, pp. 435-56.

Hopkins, K.D., Stanley, J.C. and Hopkins, B.R. (1990), Educational and Psychological Measurement and Evaluation, 7th ed., Prentice-Hall, Englewood Cliffs, NJ.

LaTour, S.A. and Peat, N.C. (1979), "Conceptual and methodological issues in consumer satisfaction research", in Wilkie, W.L. (Ed.), Advances in Consumer Research, Vol. 6, Association for Consumer Research, Ann Arbor, MI, pp. 431-7.

Loomis, J.B. (2000), "Counting on recreation use data: a call for long-term monitoring", Fournal of Leisure Research, Vol. 32 No. 11, pp. 93-6.
Lynch, J.G. Jr, Chakravarti, D. and Mitra, A. (1991), "Contrast effects in consumer judgments: changes in mental representations or in the anchoring of rating scales?", Fournal of Consumer Research, Vol. 18, December, pp. 284-97.

McPherson, B.D. (1991), in Driver, B.L., Brown, P.J. and Peterson, G.L. (Eds), Benefits of Leisure, Venture Publishing, State College, PA, pp. 423-30.

Manning, R.E. (1999), Studies in Outdoor Recreation Search and Research for Satisfaction, 2nd ed., Oregon State University, Corvallis, OR.

Mills, P.K. and Morris, J.H. (1986), "Clients as partial employees of service organizations: role development in client participation", Academy of Management Review, Vol. 11, pp. 726-35.

Mittal, B. and Lassar, W.M. (1998), "Why do customers switch? The dynamics of satisfaction versus loyalty", Fournal of Services Marketing, Vol. 12 No. 3, pp. 177-94.

Mittal, V., Katrichis, J.M. and Kumar, P. (2001), "Attribute performance and customer satisfaction over time: evidence from two field studies", Fournal of Services Marketing, Vol. 15 No. 5, pp. 343-56.

Oliver, R.L. (1980), "A cognitive model of the antecedents and consequences of satisfaction decisions", Fournal of Marketing Research, Vol. 17, November, pp. 460-9.

Oliver, R.L. (1993), “A conceptual model of service quality and service satisfaction: compatible goals, different concepts", in Swartz, T.A., Bowen, D.E. and Brown, S.W. (Eds), Advances in Marketing and Management, JAI Press, Inc., Greenwich, CT, pp. 65-85.

Parasuraman, A., Zeithaml, V.A. and Berry, L.L. (1985), "A conceptual model of service quality and its implications for future research", fournal of Marketing, Vol. 49, pp. 41-50.

Parasuraman, A., Zeithaml, V.A. and Berry, L.L. (1988), "SERVQUAL: a multiple-item scale for measuring consumer perceptions of service quality", fournal of Retailing, Vol. 64, pp. 12-40, Spring.

Parasuraman, A., Zeithaml, V.A. and Berry, L.L. (1994), "Alternative scales for measuring service quality: a comparative assessment based on psychometric and diagnostic criteria", Fournal of Retailing, Vol. 70 No. 3, pp. 201-30.

Payne, J.W., Bettman, J.R. and Johnson, E.J. (1993), The Adaptive Decision Maker, Cambridge University Press, New York, NY.

Schreyer, R. and Knopf, R.C. (1984), "The dynamics of change in outdoor recreation environments - some equity issues", Fournal of Park and Recreation Administration, Vol. 2 No. 1, pp. 9-19.

Shelby, B. and Heberlein, T. (1986), Carrying Capacity in Recreation Settings, State University Press, Corvallis, OR.

Shelby, B. and Vaske, J. (1991), "Resource and activity substitutes for recreational salmon fishing in New Zealand", Leisure Sciences, Vol. 13, pp. 21-32.

Shelby, B., Vaske, J. and Heberlein, T. (1989), "Comparative analysis of crowding in multiple locations: results from 15 years of research", Leisure Sciences, Vol. 11, pp. 269-91.

Spreng, R.A., MacKenzie, S.B. and Olshavsky, R.W. (1996), "A reexamination of the determinants of consumer satisfaction", Fournal of Marketing, Vol. 60, July, pp. 15-32.

Stewart, W.P. and Cole, D.N. (2001), "Number of encounters and experience quality in Grand Canyon backcountry: 
consistently negative and weak relationships", fournal of Leisure Research, Vol. 33 No. 1, pp. 106-20.

Taylor, S.F. (1994), "Waiting for service: the relationship between delays and evaluations of service", fournal of Marketing, Vol. 58, April, pp. 56-69.

Thompson, C.W. (2002), "Urban open space in the $21 \mathrm{st}$ century", Landscape and Urban Planning, Vol. 60, pp. 59-72.

Tian-Cole, S., Crompton, J.L. and Willson, V.L. (2002), "An empirical investigation of the relationships between service quality, satisfaction and behavioural intentions among visitors to a wildlife refuge", fournal of Leisure Research, Vol. 34 No. 1, pp. 1-24.

Tinsley, H., Tinsley, D. and Croskeys, C. (2002), "Park usage, social milieu, and psychosocial benefits of park use reported by older urban park users from four ethnic groups", Leisure Sciences, Vol. 24, pp. 199-218.

Wagar, A. (1974), "Recreational carrying capacity reconsider", Fournal of Forestry, Vol. 73, pp. 274-8.

Westbrook, R.A. and Reilly, M.D. (1983), "Value-percept disparity: an alternative to the disconfirmation of expectations theory of consumer satisfaction", in Bagozzi, R.P. and Tybout, A.M. (Eds), Advances in Consumer Research, Vol. 10, Association for Consumer Research, Ann Arbor, MI, pp. 256-61.

Williams, D. (1988), "Great expectations and the limits of satisfaction: a review of recreation and consumer satisfaction research. Outdoor recreation benchmark", Proceedings of the National Outdoor Recreation Forum, General Technical Report SE-52, USDA Forest Service, Southeastern Experiment Station, Asheville, NC, pp. 422-38.

Yi, Y. (1990), "A critical review of consumer satisfaction", in Zeithaml, V.A. (Ed.), Review of Marketing, American Marketing Association, Chicago, IL, pp. 68-123.

\section{Executive summary and implications for managers and executives}

This summary has been provided to allow managers and executives a rapid appreciation of the content of this article. Those with a particular interest in the topic covered may then read the article in toto to take advantage of the more comprehensive description of the research undertaken and its results to get the full benefits of the material present.

Eng and Niininen examine and compare individual components of service quality that influence the level of satisfaction and dissatisfaction of both frequent visitors to, and low users of, public parks. The former were defined as people who visited public parks three times or more a month, while the latter were those who visited not more than twice a month. The study was carried out in the UK county of Derbyshire.

\section{Factors contributing to visitor satisfaction}

The study reveals that comfortable settings, the landscape and the maintenance of the park were the most important priorities for frequent park visitors. Low users noted convenience, comfortable settings and the space provided by public parks as the most important positive attributes that contribute to visitor satisfaction.

\section{The main causes of dissatisfaction}

The main causes of dissatisfaction, for frequent visitors, were children's playgrounds, personal safety, the quality of refreshments and the range of facilities. Low users were also dissatisfied with these attributes, but placed range of facilities at the top of the list, followed by quality of refreshments, children's playgrounds and personal safety. The extent to which negative attributes affect visitor satisfaction were more highly rated than the positive attributes, particularly for low users. In other words, negative performance of an attribute may have a greater impact than positive performance on overall visitor satisfaction.

\section{Some of the top priorities}

High on the priority list of public park services and facilities that affect both low and high satisfaction groups significantly are good facility, landscape, range of facilities, convenience and experience at the park. Improvements in these areas would therefore have a significant effect on visitor satisfaction. The level of service provided by public parks was also noted as a major cause of visitor dissatisfaction, particularly for low users. This highlights the importance of customer service as one of the main areas for service improvement with regard to the provision of facilities and organisation of events by public parks. Interactions between park employees and visitors also play an important role in achieving high visitor satisfaction.

\section{How services and facilities could be improved}

Low users would be more likely to make more use of public parks if: information were publicised about the services and facilities they offer; plants and landscape were changed according to the time of year; safety were improved; the shops for refreshments were more accessible; and a track were provided for joggers. For frequent users, the most common suggestions for improving services and facilities were: organised recreational activities for children; improved safety, and especially better car-park lighting; good maintenance of facilities; better communication of the events, services and facilities offered; and making more creative use of space and preserving the natural environment.

\section{Pre-visit decision-making}

The facilities and services considered most important by frequent park users, in their pre-visit decision-making, were: convenient parking; child-friendly; clean; diverse range of facilities; and personal safety. The equivalent factors for low users were: the appearance of the park; peace and relaxation; range of facilities; historic interest; and children's playgrounds. The research indicates that fulfilling the needs of low users may cause them to visit the park more regularly, but fulfilling the needs of frequent park visitors may not have such a large effect on the perceived satisfaction levels of frequent visitors.

Some 68 per cent of frequent visitors, and 49 per cent of low users, said they would recommend others to use the public park.

( $A$ précis of the article "An integrative approach to diagnosing service quality of public parks". Supplied by Marketing Consultants for Emerald.) 